\title{
The Effect of Urine pH and Urinary Uric Acid Levels on the Development of Contrast Nephropathy
}

\author{
Gamze Aslan $^{a}$ Baris Afsar ${ }^{b} \quad$ Alan A. Sag ${ }^{c}$ Volkan Camkiran $^{a}$ \\ Nihan Erden ${ }^{d}$ Sezen Yilmaz ${ }^{d}$ Dimitrie Siriopole ${ }^{e}$ Said Incir ${ }^{f}$ \\ Zhiying Youg Miguel L. Garciag Adrian Covic ${ }^{\mathrm{e}}$ David Z.I. Cherney ${ }^{\mathrm{h}}$ \\ Richard J. Johnsong Mehmet Kanbay ${ }^{i}$

\begin{abstract}
${ }^{a}$ Department of Cardiology, Koc University Hospital, Istanbul, Turkey; ${ }^{b}$ Division of Nephrology, Department of Internal Medicine, Suleyman Demirel University School of Medicine, Isparta, Turkey; ${ }^{C}$ Division of Vascular and Interventional Radiology, Department of Medicine and Pharmacy "Gr. T. Popa", lasi, Romania; 'Department of Biochemistry,

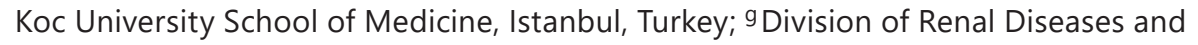
Hypertension, School of Medicine, University of Colorado Denver, Aurora, CO, USA; hDivision of Nephrology, University Health Network, University of Toronto, Toronto, Medicine, Istanbul, Turkey
\end{abstract} \\ of Radiology, Duke University Medical Center, Durham, NC, USA; dDepartment of Medicine,

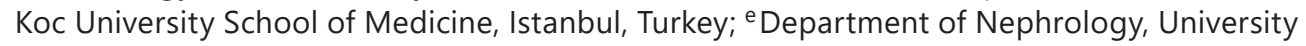 \\ ON, Canada; 'Division of Nephrology, Department of Medicine, Koc University School of
}

\section{Keywords}

Contrast nephropathy · Uric acid · Urine uric acid · Acute kidney injury

\begin{abstract}
Background: Hyperuricemia may cause acute kidney injury by activating inflammatory, prooxidative and vasoconstrictive pathways. In addition, radiocontrast causes an acute uricosuria, potentially leading to crystal formation. We therefore aimed to investigate the effect of urine acidity and urine uric acid level on the development of contrast-induced nephropathy (CIN) in patients undergoing elective coronary angiography. Methods: We enrolled 175 patients who underwent elective coronary angiography. CIN was defined as a $>25 \%$ increase in the serum creatinine levels relative to basal values $48-72 \mathrm{~h}$ after contrast use. Prior to coronary angiography and 48-72 h later, serum uric acid, urea, creatinine, bicarbonate levels, and spot uric acid to creatinine ratio (UACR) were measured. Results: Of the 175 subjects included, 29 (16.6\%) developed CIN. Those who developed CIN had a higher prevalence of diabetes, higher UACR $(0.60$ vs. $0.44, p=0.014)$, higher contrast volume, and lower serum sodium level. With univariate analysis of a logistic regression model, the risk of CIN was found to be associated with diabetes $(p=0.0016, \mathrm{OR}=3.8[95 \% \mathrm{Cl}: 1.7-8.7])$, urine UACR $(p=0.0027, \mathrm{OR}=9.6[95 \%$
\end{abstract}




\section{Kidney \\ Blood Pressure \\ Research}

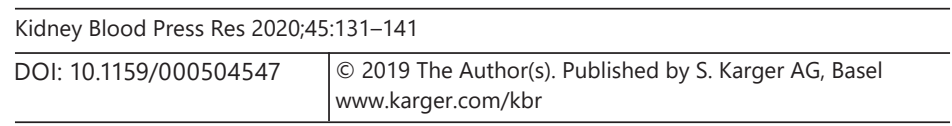

Aslan et al.: The Effect of Urine $\mathrm{pH}$ and Urinary Uric Acid Levels on the Development of Contrast Nephropathy

$\mathrm{Cl}: 2.2-42.2])$, serum sodium $(p=0.0079, \mathrm{OR}=0.8$ [95\% Cl: $0.77-0.96])$, and contrast volume ( $p=0.0385, \mathrm{OR}=1.8$ [95\% Cl: 1.03-3.09]). In a multiple logistic regression model with stepwise method of selection, diabetes ( $p=0.0120, \mathrm{OR}=3.2$ [95\% Cl: $1.3-8.1])$ and UACR $(p=0.0163$, $\mathrm{OR}=6.9$ [95\% Cl: 1.4-33.4]) were the 2 risk factors finally identified. Conclusions: We have demonstrated that higher urine UACR is associated with the development of CIN in patients undergoing elective coronary angiography.

(C) 2019 The Author(s)

Published by S. Karger AG, Basel

\section{Introduction}

Contrast-induced nephropathy (CIN) was historically a common cause of acute kidney injury (AKI) in hospitalized patients following surgery and hypotension $[1,2]$ with a significantly increased risk of mortality in short- and long-term follow-up [3]. Early studies linked contrast nephropathy with the use of high-osmolality contrast media, and biopsy studies documented a tubular lesion that resembled osmotic nephrosis [4]. Indeed, experimental studies have also identified the increased osmolal load of radiocontrast as a means for inducing the aldose reductase-fructokinase pathway in the proximal tubule, resulting in oxidative stress and tubular injury [5]. The use of low-osmolarity contrast media (which is still high relative to serum osmolality) has resulted in a lower frequency of AKI, and this has been further reduced with protocols that include minimizing the volume of contrast administered and providing hydration. As a consequence, the frequency of CIN is low [6] and likely overestimated [7]. Additionally, many clinical studies demonstrated that several novel renal biomarkers, such as neutrophil gelatinase-associated lipocalin (NGAL), cystatin C, and antithrombin III, might predict CIN earlier than serum creatinine [8-10].

Nevertheless, our group continues to see cases of AKI following radiocontrast administration, and we and others have shown that the injury can be predicted by the presence of hyperuricemia [1, 11]. Hyperuricemia activates inflammatory, pro-oxidative, and vasoconstrictive pathways and has been implicated in both acute and chronic kidney injury [12-16]. In addition, radiocontrast also may cause an acute uricosuria $[17,18]$, potentially leading to crystal formation, especially if the urine is acidic [19]. Focusing on this latter observation, we decided to test the hypothesis if urine acidity, urine uric acid level, serum bicarbonate, and serum uric acid level might be risk factors for the development of CIN in patients undergoing elective coronary angiography.

\section{Materials and Methods}

\section{Patients and Study Design}

Koc University School of Medicine ethics committee approved the study protocol. We enrolled 175 patients who were admitted to the Cardiology Department of Koc University Hospital for elective coronary angiography between January 2018 and December 2018. Data was collected prospectively regarding clinical, demographic, and laboratory findings of the patients. Patients who were older than 18 years and had an estimated glomerular filtration rate (eGFR) between 30 and $90 \mathrm{~mL} / \mathrm{min} / 1.73 \mathrm{~m}^{2}$ (according to the CKD-EPI formula) were included in this study. Written informed consent was obtained from all subjects before enrollment. Patients meeting the following criteria were excluded: age older than 80 years, dialysis patients, stage 5 chronic kidney disease, eGFR $>90 \mathrm{~mL} / \mathrm{min} / 1.73 \mathrm{~m}^{2}$, stage 4 heart failure, cardiogenic shock related to myocardial infarction, history of gout, ongoing allopurinol treatment, ongoing glomerulonephritis treatment, or diagnosis of cancer. 
CIN was defined as a $>25 \%$ increase in the serum creatinine levels relative to basal values 48-72 $\mathrm{h}$ after contrast use. The patients were divided into 2 groups based on changes in the serum creatinine values $48-72 \mathrm{~h}$ after contrast use. Patients with $\geq 25 \%$ increase in the serum creatinine values were categorized as CIN, while patients with no change or $<25 \%$ increase in the serum creatinine values were included in the control group. We also stratified subjects as control, subclinical AKI, or CIN based on the more sensitive biomarker of AKI, NGAL.

The amount of contrast and the medications used by the patients were recorded with the demographic characteristics and all other clinical data of the patients involved in this project. To help prevent the development of CIN, the use of nephrotoxic drugs, such as non-steroid antiinflammatory drugs, metformin, angiotensin-converting enzyme inhibitors, angiotensin receptor blockers, and diuretics, was stopped and hydration was given to patients following published guidelines [2]. In addition, $\mathrm{N}$-acetylcysteine $(>1,200 \mathrm{mg} /$ day) was given to all patients starting 2 days before coronary angiography and continuing until 2 days after angiography.

\section{Biochemical Analyses}

Prior to coronary angiography, 10-mL blood and 10-mL urine samples were taken from all patients. The blood sample was used to measure the uric acid, urea, creatinine, sodium ( $\mathrm{Na}$ ), potassium (K), and bicarbonate levels, while spot urine uric acid and creatinine were measured and spot uric acid to creatinine ratio (UACR) was used to obtain a result similar to that of 24-h urinary uric acid measurement from the urine sample. For additional analyses of NGAL, 10-mL blood and 10-mL urine samples were again obtained from the patients and were centrifuged and preserved at $-80^{\circ} \mathrm{C}$. To examine the renal function of patients and to determine whether CIN developed, $10-\mathrm{mL}$ blood and urine samples were taken 48-72 $\mathrm{h}$ after coronary angiography and preserved at $-80^{\circ} \mathrm{C}$ to perform the same tests again. The tests were performed simultaneously in order to avoid any bias due to methodology and calibration differences (Fig. 1). Uric acid levels were analyzed by Cobas 6000 (Roche Modular System) using enzymatic/colorimetric method.

\section{NGAL Analysis through ELISA}

For the measurement of NGAL, patients' blood samples were collected into dry tubes and centrifuged immediately $(3,500 \mathrm{~g})$ for $10 \mathrm{~min}$ at $+4^{\circ} \mathrm{C}$. Sera were separated in aliquots and frozen immediately at $-80^{\circ} \mathrm{C}$. NGAL levels in serum were determined by competitive ELISA using commercial kits (Thermo Fisher, Invitrogen, BMS2202). Intra- and inter-coefficient of variation were 4 and $5.8 \%$, respectively.

\section{Statistical Methods}

Means and standard deviations were calculated for continuous variables and counts and percentages for categorical variables. Medians and interquartile ranges were employed for contrast volume and NGAL since they are not normally distributed. CIN was diagnosed if serum creatinine increased by $25 \%$ from baseline until $48 \mathrm{~h}$ after contrast use. Numerical variables are presented as means (standard deviations) and nominals as percentages. All variables were subjected to Kolmogorov-Smirnov testing to determine whether they were normally distributed. The association of CIN with baseline variables of interest were examined: (1) the $\chi^{2}$ test and $t$ test were used to compare between CIN and non-CIN; (2) a univariate logistic regression model was used to examine the individual baseline variables; and (3) multiple regression with stepwise methods was used to screen the highly potential risk factors. With the stepwise selection, a significance level of 0.3 was required to allow a variable into the model, and a significance level of 0.35 was required for a variable to stay in the model. In addition, since higher NGAL has been considered an important and early biomarker of AKI, we defined 3 risk groups based on the tertiles of the change in NGAL from baseline to $48 \mathrm{~h}$ after contrast use (i.e., groups with the change $\leq 66.3 \mathrm{ng} / \mathrm{mL}$ [group 1], $\geq 79 \mathrm{ng} / \mathrm{mL}$ [group 3], 


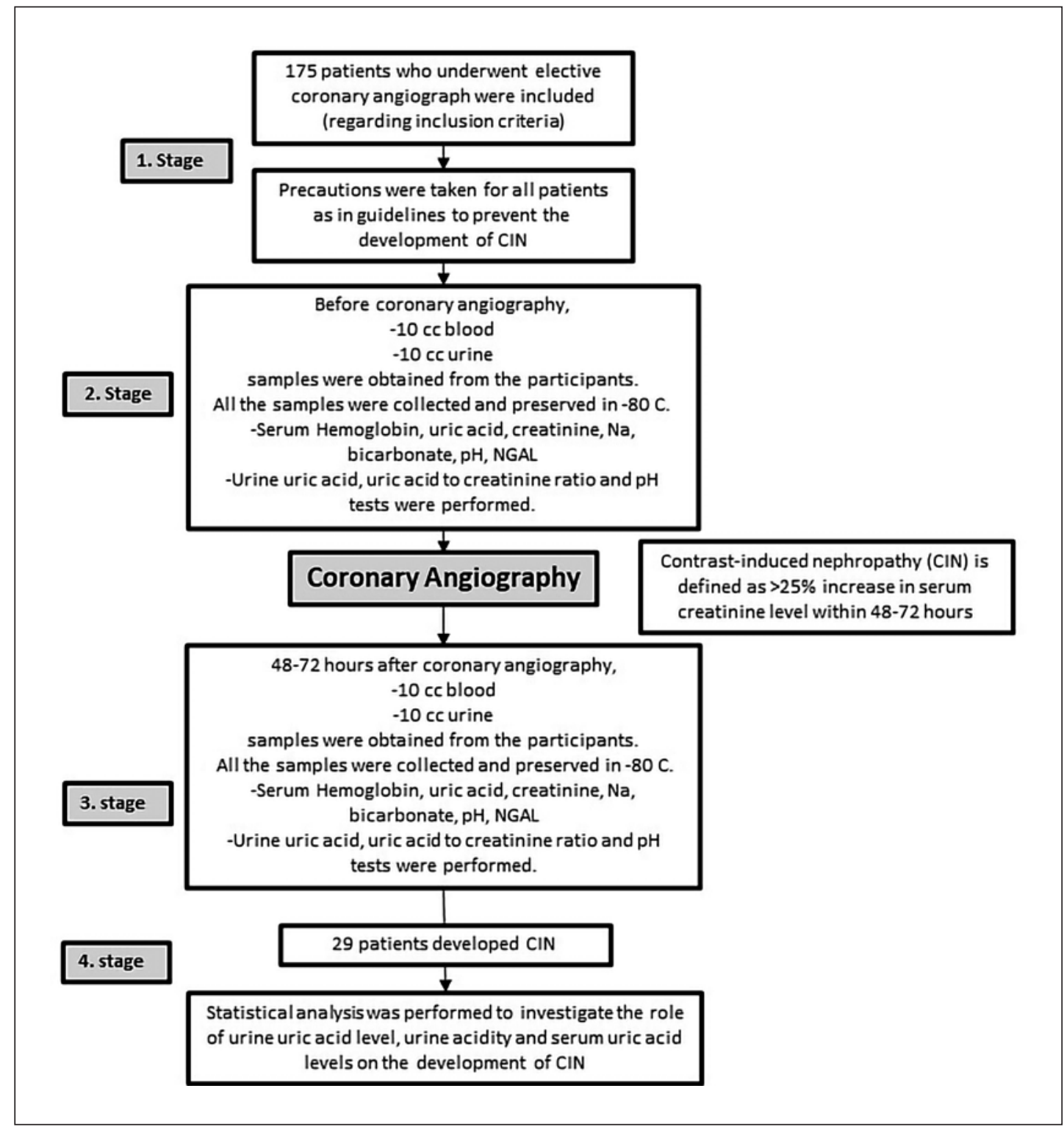

Fig. 1. Flow diagram of the study design.

and between $<79$ and $>66.3 \mathrm{ng} / \mathrm{mL}$ [group 2]) and investigated its association with CIN and other baseline variables using the $\chi^{2}$ test and analysis of variance (ANOVA) in group comparisons. The natural log values of contrast volume and NGAL were used in comparison. The twosided significance level of 0.05 was used for making a conclusion. All analyses were performed using SAS 9.4 (SAS Institute, Cary, NC, USA).

\section{Results}

The mean age of the patients was $67.6 \pm 11.2$ years and $65.7 \%$ were male. Smokers constituted $41.7 \%$ of the patients. The percentages of patients with diabetes and hypertension were 35.4 and $70.9 \%$, respectively. Of the 175 subjects included in the final analysis, 29 (16.6\%) 
Table 1. Baseline characteristics and comparison between the 2 CIN groups

\begin{tabular}{|c|c|c|c|c|}
\hline \multirow[t]{2}{*}{ Baseline variables } & \multirow[t]{2}{*}{ Total } & \multicolumn{2}{|c|}{ CIN ( $\geq 25 \%$ increased SRC) } & \multirow[t]{2}{*}{$p$ value } \\
\hline & & no $(n=146)$ & yes $(n=29)$ & \\
\hline Age, years & $67.62(11.21)$ & $67.06(11.28)$ & $70.41(10.58)$ & 0.1417 \\
\hline Male, $n(\%)$ & 115 (65.7) & $93(63.7)$ & $22(75.9)$ & 0.2075 \\
\hline Diabetes, $n(\%)$ & $62(35.4)$ & $44(30.1)$ & $18(62.1)$ & 0.0010 \\
\hline Hypertension, $n(\%)$ & $124(70.9)$ & $101(69.2)$ & $23(79.3)$ & 0.2728 \\
\hline Smoking, $n(\%)$ & $73(41.7)$ & $59(40.4)$ & $14(48.3)$ & 0.4327 \\
\hline Hemoglobin, g/dL & $12.77(2.18)$ & $12.88(2.25)$ & $12.26(1.78)$ & 0.1639 \\
\hline Creatinine, mg/dL & $1.11(0.32)$ & $1.10(0.30)$ & $1.19(0.41)$ & 0.2219 \\
\hline $\mathrm{eGFR}, \mathrm{mL} / \mathrm{min} / 1.73 \mathrm{~m}^{2}$ & $65.61(17.04)$ & $66.53(16.25)$ & $60.96(20.21)$ & 0.1074 \\
\hline Serum sodium, mmol/L & $141.07(3.37)$ & $141.39(3.13)$ & $139.48(4.08)$ & 0.0227 \\
\hline Serum $\mathrm{HCO}_{3}$, meq/L & $25.88(2.96)$ & $26.01(2.90)$ & $25.22(3.19)$ & 0.1881 \\
\hline Uric acid, mg/dL & $6.59(1.71)$ & $6.56(1.68)$ & $6.76(1.85)$ & 0.5728 \\
\hline Serum $\mathrm{pH}$ & $7.38(0.04)$ & $7.38(0.04)$ & $7.38(0.03)$ & 0.3943 \\
\hline Urine $\mathrm{pH}$ & $5.83(0.82)$ & $5.87(0.84)$ & $5.66(0.72)$ & 0.1991 \\
\hline UACR & $0.47(0.25)$ & $0.44(0.22)$ & $0.60(0.32)$ & 0.0142 \\
\hline Median contrast volume (IQR), mL & $135(80-290)$ & $125(80-250)$ & $230(120-335)$ & 0.0358 \\
\hline Median NGAL (IQR), ng/mL & $283(219-420)$ & $275(215-404)$ & $386(275-433)$ & 0.0527 \\
\hline
\end{tabular}

Values are means (SD) unless otherwise indicated. The $\chi^{2}$ test and two-samples $t$ test were used to compare the 2 groups if appropriate, and the natural log values of contrast volume and NGAL were used in comparison. CIN, contrast-induced nephropathy; SRC, serum creatinine; SD, standard deviation; eGFR, glomerular filtration rate; $\mathrm{HCO}_{3}$, bicarbonate; UACR, urine uric acid to creatinine ratio; IQR, interquartile range; NGAL, neutrophil gelatinase-associated lipocalin.

developed CIN defined as an increase by $25 \%$ in serum creatinine from baseline to $48 \mathrm{~h}$ after contrast use. Table 1 shows the baseline variables with a comparison between the 2 groups. Those who developed CIN had a higher prevalence of diabetes (62.1 vs. $30.1 \%, p=0.001$ ), lower serum sodium (139 vs. $141 \mathrm{mmol} / \mathrm{L}, p=0.022)$, higher UACR ( 0.60 vs. $0.44, p=0.014$ ), higher contrast volume ( 230 vs. $125 \mathrm{~mL}, p=0.036$ ), and higher but non-significant serum NGAL level at baseline (386 vs. $275 \mathrm{ng} / \mathrm{mL}, p=0.053$ ).

Using univariate analysis of the logistic regression model (Table 2), risk for CIN was observed with diabetes $(p=0.0016$, odds ratio [OR] $=3.8$ [95\% CI: 1.7-8.7]), serum sodium $(p=0.0079, \mathrm{OR}=0.86$ [95\% CI: 0.77-0.96]), UACR ( $p=0.0027, \mathrm{OR}=9.6$ [95\% CI: $2.2-42.2])$, and contrast volume ( $p=0.0385$, OR $=1.8$ [95\% CI: 1.03-3.09]). Using a multiple logistic regression model with stepwise method of selection, diabetes ( $p=0.0120$, OR $=3.2$ [95\% CI: 1.3-8.1]) and UACR ( $p=0.0163, \mathrm{OR}=6.9$ [95\% CI: 1.4-33.4]) were the 2 risk factors finally identified.

Urine NGAL values (as a more sensitive marker of AKI) from baseline to $48 \mathrm{~h}$ can be found in Tables 3 and 4. As shown in Tables 3 and 4, age, hemoglobin level, creatinine level, glomerular filtration rate, serum sodium level, serum bicarbonate, serum uric acid, and urine UACR were significantly different between the different tertiles of urinary NGAL. Patients in the higher NGAL tertile had a higher baseline serum uric acid and urine UACR compared to the other 2 groups.

\section{Discussion}

In this study, we investigated the role of urine uric acid levels, urine $\mathrm{pH}$, serum bicarbonate, and serum uric acid levels in the development of CIN in patients undergoing coronary angiography. We found that diabetes mellitus, high dose of contrast medium, and high urine 
Table 2. Results from univariate and multiple logistic regression models

\begin{tabular}{|c|c|c|c|c|}
\hline \multirow[t]{2}{*}{ Baseline variables } & \multicolumn{2}{|c|}{ Univariate analysis } & \multicolumn{2}{|c|}{$\begin{array}{l}\text { Variables which stayed in the final model } \\
\text { with stepwise selection }\end{array}$} \\
\hline & $p$ value & HR $(95 \%$ CI) & $p$ value & $\operatorname{HR}(95 \% \mathrm{CI})$ \\
\hline Age & 0.1429 & $1.028(0.991,1.067)$ & & \\
\hline Male & 0.2119 & $1.791(0.717,4.472)$ & 0.1245 & $2.270(0.798,6.461)$ \\
\hline Diabetes & 0.0016 & $3.793(1.655,8.693)$ & 0.0120 & $3.228(1.294,8.054)$ \\
\hline Hypertension & 0.2768 & $1.708(0.651,4.482)$ & & \\
\hline Smoking & 0.4338 & $1.376(0.619,3.063)$ & & \\
\hline Hemoglobin & 0.1647 & $0.877(0.729,1.055)$ & & \\
\hline Creatinine & 0.1304 & $2.395(0.772,7.429)$ & & \\
\hline eGFR & 0.1096 & $0.982(0.959,1.004)$ & & \\
\hline Serum sodium & 0.0079 & $0.857(0.765,0.960)$ & 0.1242 & $0.906(0.800,1.027)$ \\
\hline Serum $\mathrm{HCO}_{3}$ & 0.1884 & $0.911(0.793,1.047)$ & & \\
\hline Uric acid & 0.5706 & $1.070(0.848,1.349)$ & & \\
\hline Serum pH & 0.3927 & $0.015(<0.001,221.988)$ & & \\
\hline Urine $\mathrm{pH}$ & 0.2007 & $0.705(0.412,1.205)$ & & \\
\hline UACR & 0.0027 & $9.614(2.189,42.228)$ & 0.0163 & $6.901(1.427,33.373)$ \\
\hline Contrast volume & 0.0385 & $1.785(1.031,3.089)$ & 0.1377 & $1.579(0.864,2.888)$ \\
\hline NGAL & 0.0530 & $2.530(0.988,6.478)$ & 0.1450 & $2.204(0.762,6.382)$ \\
\hline
\end{tabular}

The natural log values of contrast volume and NGAL were used in the analysis. eGFR, glomerular filtration rate; $\mathrm{HCO}_{3}$, bicarbonate; UACR, urine uric acid to creatinine ratio; NGAL, neutrophil gelatinase-associated lipocalin.

Table 3. Baseline characteristics and comparison between the 3 groups of NGAL change

\begin{tabular}{|c|c|c|c|c|}
\hline \multirow[t]{2}{*}{ Variables } & \multicolumn{3}{|c|}{ Groups based on change in NGAL } & \multirow[t]{2}{*}{$p$ value } \\
\hline & $\leq 66.3 \mathrm{ng} / \mathrm{mL}$ & $\begin{array}{l}\text { between }<79 \\
\text { and }>66.3 \mathrm{ng} / \mathrm{mL}\end{array}$ & $\geq 79 \mathrm{ng} / \mathrm{mL}$ & \\
\hline Age, years & $63.80(10.44)$ & $70.26(11.21)$ & $68.92(10.95)$ & 0.0037 \\
\hline Male, $n(\%)$ & $40(67.8)$ & $37(63.8)$ & $39(65.0)$ & 0.8962 \\
\hline Diabetes, $n(\%)$ & $15(25.4)$ & $20(34.5)$ & $28(46.7)$ & 0.0523 \\
\hline Hypertension, $n(\%)$ & $37(62.7)$ & $44(75.9)$ & $45(75.0)$ & 0.2113 \\
\hline Smoking, $n(\%)$ & $24(40.7)$ & $26(44.8)$ & $24(40.0)$ & 0.8483 \\
\hline Hemoglobin, g/L & $13.49(1.85)$ & $12.72(2.30)$ & $12.12(2.17)$ & 0.0025 \\
\hline Creatinine, $\mathrm{mg} / \mathrm{dL}$ & $1.03(0.20)$ & $1.08(0.32)$ & $1.22(0.37)$ & 0.0024 \\
\hline eGFR, mL/min/1.73 $\mathrm{m}^{2}$ & $71.61(12.57)$ & $67.24(17.71)$ & $58.24(17.53)$ & $<0.0001$ \\
\hline Serum sodium, mmol/L & $142.42(2.31)$ & $140.69(2.90)$ & $140.22(4.20)$ & 0.0007 \\
\hline Serum $\mathrm{HCO}_{3}, \mathrm{meq} / \mathrm{L}$ & $26.35(2.96)$ & $26.17(3.16)$ & $25.11(2.58)$ & 0.0435 \\
\hline Uric acid, mg/dL & $6.49(1.57)$ & $6.15(1.49)$ & 7.10 (1.89) & 0.0084 \\
\hline Serum $\mathrm{pH}$ & $7.38(0.04)$ & $7.38(0.03)$ & $7.38(0.05)$ & 0.8361 \\
\hline Urine $\mathrm{pH}$ & $5.79(0.87)$ & $5.98(0.80)$ & $5.73(0.78)$ & 0.2243 \\
\hline UACR & $0.36(0.15)$ & $0.47(0.25)$ & $0.57(0.27)$ & $<0.0001$ \\
\hline Median contrast volume (IQR), mL & $4.86(3.91,6.41)$ & $5.04(3.55,6.35)$ & $4.92(3.22,6.40)$ & 0.8244 \\
\hline
\end{tabular}

Values are means (SD) unless otherwise indicated. The $\chi^{2}$ test and analysis of variance (ANOVA) were used if appropriate. The natural log value of contrast volume was used in comparison. NGAL, neutrophil gelatinase-associated lipocalin; eGFR, glomerular filtration rate; $\mathrm{HCO}_{3}$, bicarbonate; UACR, urine uric acid to creatinine ratio; IQR, interquartile range; SD, standard deviation. 
Table 4. Paired comparisons with the Tukey method after ANOVA as shown in Table 3

\begin{tabular}{llll}
\hline Dependent variables & \multicolumn{2}{c}{ Comparison $^{\text {a }}$} & Difference $(95 \%$ CI) \\
\hline Age & $3: \geq 79$ & $-1: \leq 66.3$ & $5.12(0.41,9.83)$ \\
& $1: \leq 66.3$ & $-2:$ between & $-6.46(-11.21,-1.71)$ \\
\hline Hemoglobin & $3: \geq 79$ & $-1: \leq 66.3$ & $-1.37(-2.29,-0.45)$ \\
\hline Creatinine & $3: \geq 79$ & $-2:$ between & $0.14(0.01,0.27)$ \\
& $3: \geq 79$ & $-1: \leq 66.3$ & $0.19(0.06,0.33)$ \\
\hline eGFR & $3: \geq 79$ & $-1: \leq 66.3$ & $-13.37(-20.35,-6.39)$ \\
& $3: \geq 79$ & $-2:$ between & $-9.00(-16.01,-1.98)$ \\
\hline Serum sodium & $1: \leq 66.3$ & $-2:$ between & $1.73(0.32,3.15)$ \\
& $3: \geq 79$ & $-1: \leq 66.3$ & $-2.21(-3.61,-0.80)$ \\
\hline Serum uric acid & $3: \geq 79$ & $-2:$ between & $0.95(0.22,1.67)$ \\
\hline UACR & $3: \geq 79$ & $-2:$ between & $0.10(0.00,0.20)$ \\
& $3: \geq 79$ & $-1: \leq 66.3$ & $0.21(0.11,0.31)$ \\
& $1: \leq 66.3$ & $-2:$ between & $-0.11(-0.21,-0.01)$ \\
\hline
\end{tabular}

Only the comparisons with a significant difference based on type I error $=0.05$ were included. eGFR, estimated glomerular filtration rate; UACR, urine uric acid to creatinine ratio. ${ }^{\text {a }}$ Numbers $1-3$ indicate tertile groups based on NGAL (ng/mL).

UACR levels were independent risk factors for the development of CIN, while serum bicarbonate levels, serum uric acid, and urine $\mathrm{pH}$ were not significant risk factors.

CIN is thought to be becoming less frequent [7]. Nevertheless, in our study, $16.6 \%$ of the patients (29 out of 175) developed CIN, and similar frequencies (10-20\%) have been reported by others $[20,21]$. CIN can result in permanent kidney damage even if renal function initially returns to normal, and the mortality risk significantly increases in high-risk patients [21]. Indeed, CIN increases short- and long-term mortality risk 2-4 times, especially in patients at high risk [22]. Therefore, identification of risk factors for CIN is important in terms of the reduction of the related complications.

Known risk factors for CIN include older age, chronic renal insufficiency, diabetes mellitus, advanced cardiovascular disease, hypotension, anemia, and high dose of contrast medium [23]. More recently, hyperuricemia has also been identified as a risk factor [1]. We identified high NGAL levels in patients with CIN. In a previous meta-analysis, Tong et al. [24] reported that increased serum and urine NGAL levels seem to be useful biomarkers in the early prediction of CIN. Additionally, high urine UACR levels were determined as an independent risk factor for the development of CIN. The identification of a high baseline urine UACR level as an independent risk factor is novel and may be relevant to the potential of radiocontrast to acutely increase urine uric acid, potentially leading to urinary crystal formation and tubular injury. Of note, diabetes is also known to cause uricosuria [25], and it is commonly identified as a risk factor for CIN, including in this study. These findings suggest that baseline urine UACR precedes and predicts acute changes in renal function and would also be consistent with uricosuria as a potential mechanism for kidney injury.

The contribution of urine acidity is known to increase the toxicity of uric acid and other toxins by increasing the chelation of urine uric acids in the tubules and renal medulla [19]. The damage of CIN occurs with a similar mechanism in tubules and medulla; however, the relationship between urine $\mathrm{pH}$ and the risk of CIN has not yet been studied. Although urine $\mathrm{pH}$ of the patients who developed CIN was lower than in the control group in our study, the 

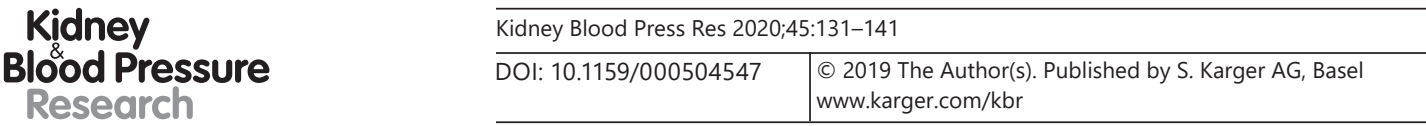

Aslan et al:: The Effect of Urine $\mathrm{pH}$ and Urinary Uric Acid Levels on the Development of Contrast Nephropathy

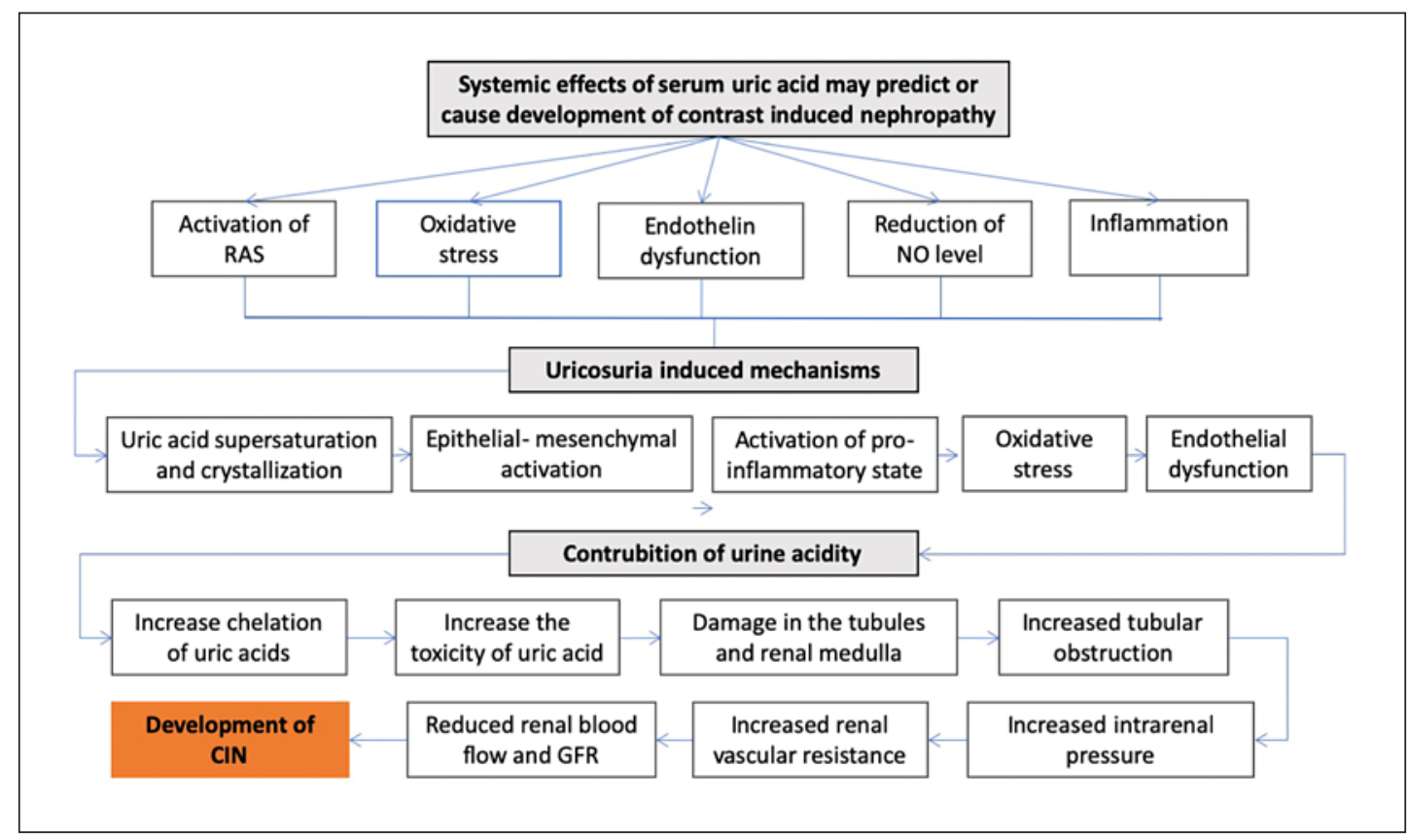

Fig. 2. Postulated mechanisms for the effect of uric acid on the development of contrast-induced nephropathy $(\mathrm{CIN})$.

difference was not statistically significant. This information supports the role of urine acidity on influencing the risk for AKI in CIN, but there is a need for a larger prospective study to identify urine $\mathrm{pH}$ as a risk factor.

Recently, high serum uric acid has also been reported to be an independent predictor for CIN in some studies [11,26-28]. Mendi et al. [1] evaluated serum uric acid as a potential risk factor for CIN in 450 patients undergoing percutaneous coronary intervention and found a serum uric acid level of $>5.4 \mathrm{mg} / \mathrm{dL}$ as a predictor for the development of CIN (sensitivity of $70 \%$, specificity of 67\%). In another study, Barbieri et al. [28] found that elevated serum uric acid ( $>7 \mathrm{mg} / \mathrm{dL}$ ) was associated with the development of CIN in patients undergoing coronary angiography or percutaneous coronary intervention (adjusted OR $=1.42$ [95\% CI: 1.04-1.93], $p=026$ ). Conversely, other studies failed to demonstrate a relationship between uric acid and CIN $[29,30]$. In the current study, patients with AKI tended to have higher baseline serum uric acid levels, and lower serum bicarbonate levels and urine $\mathrm{pH}$; however, they were not statistically different from the subjects not developing AKI.

From a therapeutic perspective, 2 prophylaxis trials have reported that allopurinol can prevent contrast nephropathy [31,32], and a recent analysis suggested that it is the most effective of all agents tried to date [33]. In contrast, Iranirad et al. [34] could not show any additional benefit of allopurinol compared to hydration for the development of CIN in highrisk patients. Likewise, another study comparing $\mathrm{N}$-acetylcysteine with allopurinol also found no significant difference in the effectiveness of these medications to prevent CIN [35].

Nevertheless, despite ongoing controversy around the effectiveness of lowering plasma uric acid pharmacologically, elevated urine uric acid levels may predispose to the development of urate crystals, leading to inflammation-related tubular injury, especially in acidic urine $[36,37]$. An increase in urine uric acid levels may also induce tubular injury through epithelial-mesenchymal transformation [38], endothelial dysfunction, oxidative stress, and elevations in C-reactive protein [39-42]. Thus, these mechanisms may in part explain why 
higher urine UACR levels were present in the patients who developed CIN in our study. Figure 2 shows the potential role of urine uric acid level and urine acidity in the pathogenesis of CIN.

In terms of limitations, the selected patients were from a single center, which, hence, may limit generalizability. The sample size was also relatively small, and we did not follow up patients in the long term. Lastly, the current study did not investigate the association between higher urine UACR and short- and long-term prognostic value, such as new cardiovascular event, mortality, and hospitalization.

In conclusion, a higher urine UACR is associated with the development of CIN in patients undergoing elective coronary angiography. Further studies are warranted to elucidate underlying mechanisms as well as randomized controlled trials with a large sample size to determine whether lowering serum uric acid and the baseline urine UACR can reduce the development of CIN.

\section{Acknowledgements}

M.K. gratefully acknowledges the use of the services and facilities of the Koc University Research Center for Translational Medicine (KUTTAM), funded by the Presidency of Turkey, Presidency of Strategy and Budget. The content is solely the responsibility of the authors and does not necessarily represent the official views of the Presidency of Strategy and Budget.

\section{Statement of Ethics}

Koc University School of Medicine ethics committee approved the study protocol. Written informed consent was obtained from all subjects before enrollment.

\section{Disclosure Statement}

All authors declare that they have no conflicts of interest.

\section{Funding Sources}

This study was not funded by any grant.

\section{Author Contributions}

Concept: G.A., M.K.; Supervision: G.A., M.K.; Materials: G.A., V.C.; Data: G.A., N.E., S.Y., V.C.; Analysis: G.A., Z.Y., M.L.G., D.Z.I.C., S.I.; Writing: G.A., M.K., D.S., B.A.

Critical revision: G.A., M.K., B.A., A.A.S., M.L.G, D.S., R.J.J., A.C.

\section{References}

1 Mendi MA, Afsar B, Oksuz F, Turak O, Yayla C, Ozcan F, et al. Uric Acid is a Useful Tool to Predict ContrastInduced Nephropathy. Angiology. 2017 Aug;68(7):627-32.

2 ACE Inhibitors in Diabetic Nephropathy Trialist Group. Should all patients with type 1 diabetes mellitus and microalbuminuria receive angiotensin-converting enzyme inhibitors? A meta-analysis of individual patient data. Ann Intern Med. 2001 Mar;134(5):370-9. 


\section{Kidney \\ Blood Pressure \\ Research}

\begin{tabular}{l|l}
\hline Kidney Blood Press Res 2020;45:131-141 \\
\hline DOI: 10.1159/000504547 & $\begin{array}{l}\text { ○ 2019 The Author(s). Published by S. Karger AG, Basel } \\
\text { www.karger.com/kbr }\end{array}$ \\
\hline
\end{tabular}

Aslan et al.: The Effect of Urine $\mathrm{pH}$ and Urinary Uric Acid Levels on the Development of Contrast Nephropathy

3 McCullough PA, Berman AD. Percutaneous coronary interventions in the high-risk renal patient: strategies for renal protection and vascular protection. Cardiol Clin. 2005 Aug;23(3):299-310.

4 Moreau JF, Droz D, Sabto J, Jungers P, Kleinknecht D, Hinglais N, et al. Osmotic Nephrosis Induced by WaterSoluble Triiodinated Contrast Media in Man. A Retrospective Study of 47 Cases. Radiology. 1975 May;115(2): 329-36.

5 Andres-Hernando A, Li N, Cicerchi C, Inaba S, Chen W, Roncal-Jimenez C, et al. Protective role of fructokinase blockade in the pathogenesis of acute kidney injury in mice. Nat Commun. 2017 Feb;8(1):14181.

6 Weisbord SD, Gallagher M, Jneid H, Garcia S, Cass A, Thwin SS, et al.; PRESERVE Trial Group. Outcomes after Angiography with Sodium Bicarbonate and Acetylcysteine. N Engl J Med. 2018 Feb;378(7):603-14.

7 Wilhelm-Leen E, Montez-Rath ME, Chertow G. Estimating the Risk of Radiocontrast-Associated Nephropathy. J Am Soc Nephrol. 2017 Feb;28(2):653-9.

8 Bachorzewska-Gajewska H, Malyszko J, Sitniewska E, Malyszko JS, Poniatowski B, Pawlak K, et al. NGAL (neutrophil gelatinase-associated lipocalin) and cystatin C: are they good predictors of contrast nephropathy after percutaneous coronary interventions in patients with stable angina and normal serum creatinine? Int J Cardiol. 2008 Jul;127(2):290-1.

9 Wu R, Kong Y, Yin J, Liang R, Lu Z, Wang N, et al. Antithrombin III is a Novel Predictor for Contrast Induced Nephropathy After Coronary Angiography. Kidney Blood Press Res. 2018;43(1):170-80.

10 Lu Z, Cheng D, Yin J, Wu R, Zhang G, Zhao Q, et al. Antithrombin III Protects Against Contrast-Induced Nephropathy. EBioMedicine. 2017 Mar;17:101-7.

11 Kanbay M, Solak Y, Afsar B, Nistor I, Aslan G, Çağlayan OH, et al. Serum Uric Acid and Risk for Acute Kidney Injury Following Contrast. Angiology. 2017 Feb;68(2):132-44.

12 Kanbay M, Segal M, Afsar B, Kang DH, Rodriguez-Iturbe B, Johnson RJ. The role of uric acid in the pathogenesis of human cardiovascular disease. Heart. 2013 Jun;99(11):759-66.

13 Kanbay M, Afsar B, Siriopol D, Unal HU, Karaman M, Saglam M, et al. Relevance of uric acid and asymmetric dimethylarginine for modeling cardiovascular risk prediction in chronic kidney disease patients. Int Urol Nephrol. 2016 Jul;48(7):1129-36.

14 Kanbay A, Inonu H, Solak Y, Erden A, Uslu E, Yuksel SA, et al. Uric acid as a potential mediator of cardiovascular morbidity in obstructive sleep apnea syndrome. Eur J Intern Med. 2014 Jun;25(5):471-6.

15 Kanbay M, Afsar B, Covic A. Uric acid as a cardiometabolic risk factor: to be or not to be. Contrib Nephrol. 2011; 171:62-7.

16 Kanbay M, Ikizek M, Solak Y, Selcoki Y, Uysal S, Armutcu F, et al. Uric acid and pentraxin-3 levels are independently associated with coronary artery disease risk in patients with stage 2 and 3 kidney disease. Am J Nephrol. 2011;33(4):325-31.

17 Kelley WN. Uricosuria and x-ray contrast agents. N Engl J Med. 1971 Apr;284(17):975-6.

18 Postlethwaite AE, Kelley WN. Uricosuric effect of radiocontrast agents. A study in man of four commonly used preparations. Ann Intern Med. 1971 Jun;74(6):845-52.

19 Preitner F, Laverriere-Loss A, Metref S, Da Costa A, Moret C, Rotman S, et al. Urate-induced acute renal failure and chronic inflammation in liver-specific Glut9 knockout mice. Am J Physiol Renal Physiol. 2013 Sep; 305(5):F786-95.

20 Newhouse JH, Kho D, Rao QA, Starren J. Frequency of serum creatinine changes in the absence of iodinated contrast material: implications for studies of contrast nephrotoxicity. AJR Am J Roentgenol. 2008 Aug;191(2): 376-82.

21 Solomon RJ, Mehran R, Natarajan MK, Doucet S, Katholi RE, Staniloae CS, et al. Contrast-induced nephropathy and long-term adverse events: cause and effect? Clin J Am Soc Nephrol. 2009 Jul;4(7):1162-9.

22 Faggioni M, Mehran R. Preventing Contrast-induced Renal Failure: A Guide. Interv Cardiol (Lond). 2016 Oct; 11(2):98-104.

23 Mehran R, Aymong ED, Nikolsky E, Lasic Z, Iakovou I, Fahy M, et al. A simple risk score for prediction of contrast-induced nephropathy after percutaneous coronary intervention: development and initial validation. J Am Coll Cardiol. 2004 Oct;44(7):1393-9.

24 Tong J, Li H, Zhang H, Luo Z, Huang Y, Huang J, et al. Neutrophil Gelatinase-associated Lipocalin in the Prediction of Contrast-induced Nephropathy: A Systemic Review and Meta-analysis. J Cardiovasc Pharmacol. 2015 Sep; 66(3):239-45.

25 Lytvyn Y, Škrtić M, Yang GK, Yip PM, Perkins BA, Cherney DZ. Glycosuria-mediated urinary uric acid excretion in patients with uncomplicated type 1 diabetes mellitus. Am J Physiol Renal Physiol. 2015 Jan;308(2):F77-83.

26 Hahn K, Kanbay M, Lanaspa MA, Johnson RJ, Ejaz AA. Serum uric acid and acute kidney injury: A mini review. J Adv Res. 2017 Sep;8(5):529-36.

27 Saritemur M, Turkeli M, Kalkan K, Tanboga IH, Aksakal E. Relation of uric acid and contrast-induced nephropathy in patients undergoing primary percutaneous coronary intervention in the ED. Am J Emerg Med. 2014 Feb;32(2):119-23.

28 Barbieri L, Verdoia M, Schaffer A, Cassetti E, Marino P, Suryapranata H, et al.; Novara Atherosclerosis Study Group (NAS). Uric acid levels and the risk of Contrast Induced Nephropathy in patients undergoing coronary angiography or PCI. Nutr Metab Cardiovasc Dis. 2015 Feb;25(2):181-6.

29 Karabulut A, Sahin I, Ilker Avci I, Okuyan E, Dogan Z, Uzunlar B, et al. Impact of serum alkaline phosphatase level on the pathophysiologic mechanism of contrast-induced nephropathy. Kardiol Pol. 2014;72(10):977-82. 
30 Kowalczyk J, Francuz P, Swoboda R, Lenarczyk R, Sredniawa B, Golda A, et al. Prognostic significance of hyperuricemia in patients with different types of renal dysfunction and acute myocardial infarction treated with percutaneous coronary intervention. Nephron Clin Pract. 2010;116(2):c114-22.

31 Erol T, Tekin A, Katırcıbașı MT, Sezgin N, Bilgi M, Tekin G, et al. Efficacy of allopurinol pretreatment for prevention of contrast-induced nephropathy: a randomized controlled trial. Int J Cardiol. 2013 Aug;167(4): 1396-9.

32 Kumar A, Bhawani G, Kumari N, Murthy KS, Lalwani V, Raju CN. Comparative study of renal protective effects of allopurinol and $\mathrm{N}$-acetyl-cysteine on contrast induced nephropathy in patients undergoing cardiac catheterization. J Clin Diagn Res. 2014 Dec;8(12):HC03-07.

33 Ahmed K, McVeigh T, Cerneviciute R, Mohamed S, Tubassam M, Karim M, et al. Effectiveness of contrast-associated acute kidney injury prevention methods; a systematic review and network meta-analysis. BMC Nephrol. 2018 Nov; 19(1):323.

34 Iranirad L, Sadeghi MS, Bagheri A, Doostali K, Norouzi S, Hejazi SF, et al. Allopurinol prophylactic therapy and the prevention of contrast-induced nephropathy in high-risk patients undergoing coronary angiography: A prospective randomized controlled trial. ARYA Atheroscler. 2017 Sep;13(5):230-5.

35 Sadineni R, Karthik KR, Swarnalatha G, Das U, Taduri G. N-acetyl cysteine versus allopurinol in the prevention of contrast nephropathy in patients with chronic kidney disease: A randomized controlled trial. Indian J Nephrol. 2017 Mar-Apr;27(2):93-8.

36 Ejaz AA, Alquadan KF, Dass B, Shimada M, Kanbay M, Johnson RJ. Effects of Serum Uric Acid on Estimated GFR in Cardiac Surgery Patients: A Pilot Study. Am J Nephrol. 2015;42(6):402-9.

37 Schepers MS, van Ballegooijen ES, Bangma CH, Verkoelen CF. Crystals cause acute necrotic cell death in renal proximal tubule cells, but not in collecting tubule cells. Kidney Int. 2005 Oct;68(4):1543-53.

38 Ryu ES, Kim MJ, Shin HS, Jang YH, Choi HS, Jo I, et al. Uric acid-induced phenotypic transition of renal tubular cells as a novel mechanism of chronic kidney disease. Am J Physiol Renal Physiol. 2013 Mar;304(5):F471-80.

39 Aykas F, Solak Y, Erden A, Bulut K, Dogan S, Sarli B, et al. Persistence of cardiovascular risk factors in women with previous preeclampsia: a long-term follow-up study. J Investig Med. 2015 Apr;63(4):641-5.

40 Kanbay M, Huddam B, Azak A, Solak Y, Kadioglu GK, Kirbas I, et al. A randomized study of allopurinol on endothelial function and estimated glomular filtration rate in asymptomatic hyperuricemic subjects with normal renal function. Clin J Am Soc Nephrol. 2011 Aug;6(8):1887-94.

41 Kanbay M, Siriopol D, Nistor I, Elcioglu OC, Telci O, Takir M, et al. Effects of allopurinol on endothelial dysfunction: a meta-analysis. Am J Nephrol. 2014;39(4):348-56.

42 Kanbay M, Yilmaz MI, Sonmez A, Solak Y, Saglam M, Cakir E, et al. Serum uric acid independently predicts cardiovascular events in advanced nephropathy. Am J Nephrol. 2012;36(4):324-31. 